\title{
CARACTERÍSTICAS CLÍNICAS E LABORATORIAIS DE MENINGITES PIOGÊNICAS EM ADULTOS
}

\author{
IRÊNIO GOMES*, RITA LUCENA*, AILTON MELO**
}

\begin{abstract}
RESUMO - Foram analisados dados do prontuário de 176 pacientes com idade igual ou superior a 15 anos, internados no Hospital Couto Maia, no período de janeiro de 1990 a dezembro de 1992. em Salvador-BA, com o diagnóstico de meningite piogênica. Observamos, em ordem decrescente, maior percentagem de pacientes com N. meningitidis $(56,7 \%)$, S. pneumoniae $(37,5 \%)$ e E.coli. (3,3\%). A letalidade foi maior no grupo com meningite pneumocócica. No grupo de indivíduos com meningite por pneumococo verificamos que a média etária e de leucбcitos no sangue periférico foram superiores quando comparadas com o grupo de portadores de meningite meningocócica. Por outro lado, neste último grupo a média de glicorraquia foi maior. A presença de lesōes cutâneas hemorrágicas mostrou-se preditora da etiologia meningocócica.
\end{abstract}

PALAVRAS-CHAVE: meningite bacteriana, septicemia, adulto, infeç̧ão do sistema nervoso central.

Clinical and laboratorial characteristics of pyogenic meningitis in adults

ABSTRACT - We reviewed the charts of 176 adult patients, admitted with a diagnosis of acute bacterial meningitis, in the Hospital Couto Maia, from January 1990 to December 1992. All the patients had community-acquired meningitis. In 120 patients we could identify the causative agent on Gram's staining and culture. The most common pathogens were $N$. meningitidis $(56.7 \%)$ S. pneumoniae (37.5\%) and $E$. coli $(3.3 \%)$. The overall lethality rate was $19.8 \%$ and the lethality was greater in the group with streptococcus meningitis $(31.8 \%)$. The mean age and the leukocyte in the peripheral blood were greater in the group with $S$. pneumoniae meningitis than in the meningococal group. Cutaneous hemorrhagic lesions was an excellent predictor meningococcal meningitis.

KEY WORDS: bacterial meningitis, adults, septicemia, central nervous system infection.

Apesar da disseminação de medidas sanitárias em todo o mundo, meningite piogênica ainda permanece como doença endêmica nos países subdesenvolvidos ou em desenvolvimento ${ }^{3,4,6-8}$. No Brasil, onde as condições de vida da maioria da população são precárias, continuamos com a incidência e letalidade de meningites muito superiores àquelas observadas em países desenvolvidos ${ }^{1,6,8}$, devido, provavelmente, à falta de condiçōes sanitárias e de investimento na prevençāo dessa enfermidade. $\mathrm{Na} \mathrm{Bahia,} \mathrm{o} \mathrm{Hospital} \mathrm{Couto} \mathrm{Maia} \mathrm{(HCM),} \mathrm{que} \mathrm{se} \mathrm{constitui} \mathrm{na} \mathrm{referência} \mathrm{do} \mathrm{Estado} \mathrm{para} \mathrm{o} \mathrm{tratamento}$ de doenças infecciosas, continua admitindo, aproximadamente, 1000 casos de meningites ao ano, das quais em tomo de 60\% são piogênicas (Serviço de Vigilância Sanitária do HCM). Em nosso Estado, à semelhança de outras regiōes, a doença é mais incidente em crianças ${ }^{2,6,8}$; no entanto, encontramos grande contingente de adultos que são internados com o diagnóstico de meningite $\mathrm{e}$ poucos sāo os estudos que se dedicam a esse grupo populacional ${ }^{5,12}$.

Neste artigo, analisamos as características clinicas e laboratoriais das meningites bacterianas, em pacientes com idade igual ou superior a 15 anos, internados no Hospital Couto Maia no período de janeiro de 1990 a dezembro de 1992.

Divisão de Neuroepidemiologia e Neuroinfectologia do Hospital Couto Maia, Departamento de NeuroPsiquiatria da Universidade Federal da Bahia (UFBA): *Pós-Graduando; **Livre Docente, Chefe de Serviço. Aceite: 6-junho-1997.

Dr. Ailton de Melo - Faculdade de Medicina UFBA - Av. Reitor Miguel Calmon s/n - 40110-100 Salvador BA - Brasil. 


\section{MÉtodos}

Foram analisadas informaçōes dos prontuários de todos os pacientes com idade superior a 15 anos internados no Hospital Couto Maia, em Salvador-Bahia, que preencheram os critérios para meningite piogênica, segundo descrito previamente ${ }^{6,8}$. Também foram considerados portadores de meningite piogênica todos os pacientes com celularidade liquórica igual ou superior a $1800 / \mathrm{mm}^{3} 11$.

As informaçōes referentes ao sexo, faixa etária, etiologia, dados clínicos e laboratoriais foram registrados em questionários e posteriormente inseridos em um banco de dados (Fox Pro, versăo 2.5) sendo analisados com a ajuda de pacote estatístico (EPI-INFO, versão 6.0).

\section{RESULTADOS}

No período de janeiro de 1990 a dezembro de 1992 foram admitidos no Hospital Couto Maia 545 casos de meningites em paciente com idade igual ou superior a 15 anos. Neste grupo $22,1 \%$ dos pacientes tinham meningite piogênica com agente identificado através da coloração pelo método de Gram ou da cultura do líquor, e 10,2\% tiveram o diagnóstico de meningite piogênica caracterizado por celularidade liquorica igual ou superior a $1800 \mathrm{cel} / \mathrm{mm}^{3}$.

Entre os 176 casos selecionados, $120(68,2 \%)$ tiveram etiologia definida por cultura ou Gram no líquor. Nos demais a etiologia nāo foi identificada. No grupo com etiologia definida, verificamos maior número de infecção por $N$. meningitidis, seguido de $S$. pneumoniae e $E$. coli. Infecção por $H$. influenzae foi encontrada em apenas 1 paciente (Tabela 1). A letalidade global foi 19,8\%, não havendo diferença significante quando considerada em relação à média do tempo de doença (KruskallWallis $=0,23 \mathrm{p}=0,63$ ).

Considerando os dois agentes mais frequentes, $N$. meningitidis e $S$. pneumoniae, observamos distribuição semelhante por sexo, com predomínio do sexo masculino em ambos. A distribuição por idade foi estatisticamente diferente com maior média nos casos de meningite pneumocócica.

Em relação à apresentação clínica, a ocorrência de vômitos, rigidez de nuca, alteração do nível de consciência (sonolência, torpor ou coma) e crises epilépticas foi semelhante nos dois grupos(Tabela 2), o mesmo acontecendo com o tempo de doença, aqui considerado como sendo o intervalo entre o aparecimento do primeiro sintoma (cefaléia, vômito, febre) e o diagnóstico de meningite (Tabela 3).

Lesōes cutâneas hemorrágicas foram encontradas em $20(41,6 \%)$ pacientes com etiologia meningocócica e em apenas um paciente com meningite pneumocócica (Tabela 2). Nos casos com meningite meningocócica, não houve diferença de letalidade nos grupos com ou sem lesão hemorrágica $(\chi 2=2,78 \mathrm{p}=0,095)$.

Tabela 1. Distribuiçāo das meningites piogênicas por agente etiológico em individuos com idade igual ou superior a 15 anos, admitidos no HCM entre janeiro de 1990 e dezembro de 1992.

\begin{tabular}{ccc}
\hline Agente Etiologico & $\mathrm{n}$ & $\%$ \\
\hline N. meningitides & 68 & 56,7 \\
S. pneumoniae & 45 & 37,5 \\
E. coli & 04 & 3,3 \\
H. influenzae & 01 & 0,83 \\
Outros & 02 & 1,67 \\
Total & 120 & 100 \\
\hline
\end{tabular}


Tabela 2. Apresentação clínica em portadores de meningite pneumocócica e meningocócica com idade igual ou superior a 15 anos admitidos no HCM entre janeiro de 1990 e dezembro de 1992.

\begin{tabular}{lcccccc}
\hline Dados clínicos & \multicolumn{2}{c}{$N$ meningitides } & \multicolumn{2}{c}{ S. pneumoniae } & X2 & p \\
& $\mathrm{n}$ & $(\%)$ & $\mathrm{n}$ & $(\%)$ & & \\
\hline Vômito & 47 & $(69,1)$ & 28 & $(62,2)$ & 0,31 & 0,58 \\
Alteração do nível de consciência & 35 & $(52,2)$ & 31 & $(68,9)$ & 2,43 & 0,11 \\
Crise epiléptica & 9 & $(13,4)$ & 4 & $(10,0)$ & 0,13 & 0,71 \\
Rigidez de nuca & 53 & $(77,9)$ & 36 & $(80,0)$ & 0,19 & 0,91 \\
Lesర̃es cutâneas hemorrágicas & 20 & $(41,6)$ & 1 & $(2,3)$ & 11,5 & $<0,001$ \\
Letalidade & 8 & $(12,3)$ & 14 & $(31,8)$ & 6,61 & 0,04 \\
\hline
\end{tabular}

Três pacientes com meningite meningocócica e um pneumocócica foram transferidos. Nos demais observamos letalidade de $31,8 \%$ nos pacientes com meningite por $S$. pneumoniae e $12,3 \%$ naqueles com meningite meningocócica, diferença estatisticamente significante (Tabela 2).

No grupo com meningite pneumocócica a média da contagem global de leucócitos no sangue periférico foi superior àquela observada nos casos de meningite meningocócica $(p=0,021)$. No entanto, a média da percentagem de bastonetes foi semelhante nos dois grupos (Tabela 3).

Os parâmetros liquóricos se comportaram da seguinte forma: as médias de celularidade e proteinorraquia foram semelhantes para meningites pneumocócica e meningocócica, mas as de glicorraquia mostraram diferença estatisticamente significante, sendo mais baixa nos casos de meningite causada por S. pneumoniae (Tabela 3).

\section{DISCUSSĀO}

Apesar das elevadas taxas de incidência e letalidade para meningites comunitárias encontradas em regiões subdesenvol vidas do planeta, são escassas as pesquisas relativas a esse tema. Na América Latina, encontramos poucas publicações a respeito dessa afecção, ${ }^{4}$. A maioria é de autores brasileiros ${ }^{2.6,8}$, sendo algumas relacionadas aos períodos de epidemias.

Tabela 3. Médias de dados clínicos e laboratoriais em portadores de meningite pneumocócica e meningocócica com idade igual ou superior a 15 anos admitidos no HCM entre janeiro de 1990 e dezembro de 1992.

\begin{tabular}{lcccccc}
\hline Variável & \multicolumn{2}{c}{$N$. meningitides } & \multicolumn{2}{c}{ S. pneumoniae } & Kruskall- & p \\
& $\mathrm{m}$ & $\mathrm{dp}$ & $\mathrm{m}$ & $\mathrm{dp}$ & Wallis & \\
\hline Idade (anos) & 27,9 & 13,7 & 39,5 & 15,8 & 15,42 & $<0,001$ \\
Tempo de doença (dias) & 5,84 & 7,95 & 3,45 & 3,2 & 0,36 & 0,54 \\
Pleocitose (cel/mm ${ }^{3}$ ) & 6799,7 & 4037 & 5436,6 & 4346,4 & 3,26 & 0,07 \\
Proteinorraquia & 367 & 148 & 493 & 698 & 0,75 & 0,38 \\
Glicorraquia & 31,8 & 15,7 & 26,0 & 12,6 & 4,2 & 0,004 \\
Leucograma (cel/mm & 12384,8 & 5515,1 & 15880,6 & 7813,2 & 5,27 & 0,021 \\
Bastões (\%) & 7,24 & 6,88 & 6,48 & 5,47 & 0,018 & 0,89 \\
\hline
\end{tabular}


No Brasil, apesar do reconhecimento da gravidade do problema pelas autoridades, pouco se tem feito para diminuir a incidência das meningites bacterianas agudas. Assim, enquanto em países como os Estados Unidos a maior preocupação se concentra no aumento de casos nosocomiais ${ }^{5}$, na nossa população permanece a grande frequência de pacientes com meningites comunitárias ${ }^{6,8}$. Ao mesmo tempo, continuamos com alto índice de letalidade decorrente principalmente da dificuldade para se fazer o diagnóstico correto aliado à falta de antibióticos adequados nos hospitais gerais.

$\mathrm{Na}$ Bahia, houve decréscimo na letalidade de meningites em geral e principalmente de meningites de etiologia pneumocócica, a qual apresentava uma letalidade de $59 \%$ no período de 1973 a $1982^{2}$. É importante salientar que, na mesma época, a taxa de letalidade para meningite meningocócica foi $14 \%$, muito próxima àquela que encontramos. Acreditamos que a queda do número de mortos por meningites pneumocócicas se deve à maior facilidade de acesso do paciente, principalmente do interior do Estado, para o hospital de referência, o que possibilita o diagnóstico e a instituição da terapêutica adequada. No caso das meningites meningocócica, a introdução do antibiótico, mesmo empiricamente, é mais rápida, provavelmente pela dramaticidade do quadro sistêmico. Isto é sugerido pela alta proporção de indivíduos admitidos com lesões cutâneas hemorrágicas $(41,6 \%)$. Neste estudo observamos grande semelhança dos nossos resultados com aqueles obtidos por outros autore ${ }^{3-5.9}$. Salientamos que foram semelhantes a presença de rash cutâneo como preditor de meningite meningocócica e a maior letalidade nos casos de meningite pneumocócica.

Taxa mais elevada de leucócitos comportou-se, na nossa população, como variável preditora da etiologia pneumocócica, o mesmo acontecendo com níveis mais baixos de glicorraquia. Entretanto, ao contrário de outros estudos nos quais foi observada maior frequência de meningite pneumocócica ${ }^{5.9 .10 .12}$, verificamos que o principal agente etiológico de meningite piogênica em pacientes com idade superior a 14 anos foi o meningococo.

Mesmo considerando a queda na mortalidade global por meningites, continuamos com níveis superiores àqueles observados em outros países ${ }^{1}$. No entanto, ainda mais preocupante é o aumento absoluto e proporcional das meningites comunitárias em nosso Estado, quando comparamos o período de 1973 a 1982 com o de janeiro de 1990 a dezembro de 1992. Os dados apresentados chamam a atenção para a urgência em se instituir políticas adequadas de saúde, provenientes de informações geradas cientificamente, que possam diminuir a alarmante incidência, morbidade e mortalidade por meningites que assolam nossa população.

\section{REFERÊNCIAS}

1. Baraff LJ, Lee SI, Scheringer DL. Outcomes of bacterial meningitis in children: a meta-analysis. Pediatr Infect Dis $J$ 1993;12:389-394.

2. Bryan JP, Silva HR, Tavares A, Rocha H, Scheld WM. Etiology and mortality of bacterial meningitis in Northeastern Brazil. Rev Inf Dis 1990;12:128-135.

3. Cadoz M, Denis F, Diop Mar I. Etude épidémiologique des cas de méningites purulentes hospitalisés à Dakar pendant la décennie 1970-79. Bulll Org Mond Santé 1981;59:575-584.

4. Chérigo-Quirós EZ, Rodriguez-French A. Meningitis bacteriana en el Hospital Santo Tomás (1975-1982). Rev Med Panama 1984;9:35-44.

5. Durand ML, Calderwood SB, Weber DJ, Miller SI, Southwick FS, Caviness VR, Swartz MN. Acute bacterial meningitis in adults: a review of 493 episodes. N Engl J Med 1993;328:21-27.

6. Gomes I, Melo A, Lucena R, Cunha-Nascimento MH, Ferreira A, Goes.J, Barreto I, Jones N, Gaspari V, Embiruçu EK. Veiga M. Prognosis of bacterial meningitis in children. Arq Neuropsiquiatr 1996;54:407-411.

7. Juliet C, Rodríguez G, Marti A, Burgos OV. Meningitis bacteriana en el niño: experiencia con 441 casos. Rev Med Child 1983;111:690-698.

8. Lucena R, Gomes I, Ferreira A, Goes J, Araújo I, Veiga M, Melo A. Características clínicas e laboratoriais de meningites bacterianas. Arq Neuropsiquiatr 1996;54:571-576.

9. Pfister HW, Feiden W, Einhaupl KM. Spectrum of complications during bacterial meningitis in adults: results of a prospective clinical study. Arch Neurol 1993;50:575-581.

10. Quagliarello V, Scheld WM. Bacterial meningitis: pathogenesis, pathophysiology and progress. N Engl J Med 1992;327:864-872.

11. Spanos A, Harrel FE, Durack DT. Differential diagnosis of acute meningitis: an analysis of the predictive value of initial observations. JAMA 1989;262:2700-2707.

12. Tunkel AR, Wispelwey $B$, Scheld M. Bacterial meningitis: recent advances in pathophysiology and treatment. Ann Intern Med 1990;112:610-623. 